\title{
Advances in thickened tailings pumping using centrifugal pumps
}

\author{
A. Sellgren Luleå University of Technology, Sweden
}

\section{Abstract}

Reduction in pumping head and efficiency and unstable head observations at flow rates below about 50\% of the best efficiency point (BEP) are discussed based on experimental results for solids concentrations by volume of up to $49 \%$ with authentic tailings products for a 0.1 by $0.075 \mathrm{~m}$ pump with impellers (diameter $0.31 \mathrm{~m}$ ) of different configurations. Yield stresses were up to $200 \mathrm{~Pa}$ as an average and evaluated from pipeline loop testing. It has been reported for highly concentrated slurries that cavitational behaviour with drops in head and efficiency may occur at lower flow rates than that of water in the BEP-region. The experimental data for the tailings above did not cover this region. However, test data were available for the same type and size of standard pump by Kabamba (2007) for a kaolin slurry with a yield stress of $185 \mathrm{~Pa}$. Evaluations here showed incipient cavitation from about $75 \%$ of the BEP-flow rate. Deratings in head and efficiency and effects related to unstable head tendencies and suction performance can be expected to diminish for pumps larger than the unit focused on here.

\section{$1 \quad$ Introduction}

With thickened tailings, only a fraction of water used conventionally reaches the disposal area, thus limiting the size of water holding dam facilities and areas to be rehabilitated. The economical feasibility, however, is site specific. At many locations the cost for a frequently returning conventional dam rise may correspond to the investment for a complete thickened tailings system. Another concern is dam safety, some reported tailings dam failures and incidents may be related to large amounts of water in the disposal area.

Centrifugal slurry pumps are used for pumping paste-like thickened tailings over short distances and for circulating the slurry in the thickener. Positive displacement pumps are used in high-pressure applications where centrifugal pumps can also be used to feed the high-pressure pumps. An overall comparison (Sellgren et al., 2005) indicated that centrifugal pumps in series for $300 \mathrm{t} / \mathrm{h}$ and $4 \mathrm{MPa}$ over a distance of $1,000 \mathrm{~m}$ would compete well with a positive displacement pump system.

\section{1 Thickener location}

With a tailings system that includes a thickener that produces a highly concentrated underflow, the thickener can be placed at the concentrator or near the disposal area. It may be favourable to locate the thickener close to the disposal area when deposition takes place along a steep hill side or down a valley, where discharge from an artificial ramp or tower is not required, see Figure 1.

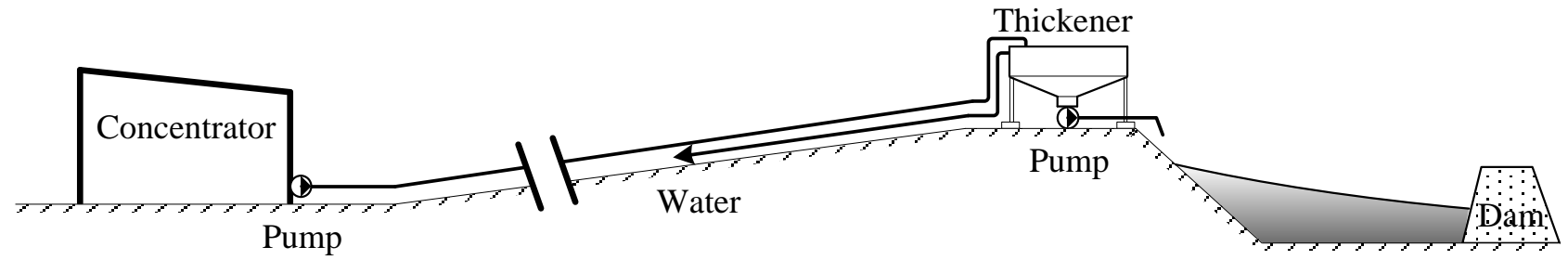

Figure 1 Schematic description of a thickened tailings system with the thickener located on hill close to the disposal area (Wennberg, 2010) 
In addition to site-specific conditions, the location of the thickener is mainly a balance of the cost of high pressure pumping and the disadvantage of having the thickening facility remote from the rest of the processing taking place in the concentrator.

Paterson (2005) presented a cost comparison between pumping $450 \mathrm{t} / \mathrm{h}$ of dry tailings as a dilute thickener feed at $14 \mathrm{w} \%$ to a remote thickener located at the disposal area. The result indicated that the remote thickener location for a distance of less than $2.5 \mathrm{~km}$ may be cost effective compared to a location at the process plant which uses a high-pressure positive displacement pump transporting thickened tailings. The study considered pump and pipeline system capital and operating cost excluding costs associated with preparation and deposition as well as extra costs for operating a remotely located thickener and circulation of water back to the concentrator.

The influence of feed slurry concentration and elevation difference between the concentrator and the feed delivery to the thickener will be schematically demonstrated in an example as a complement to the study by Paterson (2005). A capacity of $80 \mathrm{dry} t / \mathrm{h}$ is considered to be pumped about $2,000 \mathrm{~m}$ from a concentrator with delivery to the thickener at a $20 \mathrm{~m}$ higher elevation on a hill or a rim (Figure 1). Dependent upon how the direct recovery of water is arranged at the concentrator, two alternatives are assumed for the solids content in the conventional tailings transportation system, about 21 and $33 \mathrm{w} \%$. Operating data have been determined for two corresponding standard pipeline diameters assuming a tailings product characterised by an average particle size of about $50 \mu \mathrm{m}$ with maximum particles of up to $300-400 \mu \mathrm{m}$ and a solids density of $2,800 \mathrm{~kg} / \mathrm{m}^{3}$, see Table 1 . Total pump efficiency is assumed to be $70 \%$.

Table 1 Operating data for dilute feed pumping with the thickener located 2, $000 \mathrm{~m}$ from the concentrator with delivery at a $20 \mathrm{~m}$ higher elevation. Capacity $80 \mathrm{t} / \mathrm{h}$ for a tailings product with average size about $50 \mu \mathrm{m}$ with maximum particles of up to $300-400 \mu \mathrm{m}$ and a solids density of $2,800 \mathrm{~kg} / \mathrm{m}^{3}$

\begin{tabular}{lcc}
\hline Solids concentration by mass & $20.6 \%$ & $32.9 \%$ \\
Pipeline diameter & $0.25 \mathrm{~m}$ & $0.20 \mathrm{~m}$ \\
Flow rate of slurry & $337 \mathrm{~m}^{3} / \mathrm{h}$ & $192 \mathrm{~m}^{3} / \mathrm{h}$ \\
Static head & 20 & 20 \\
Friction loss gradient & 23 & 25 \\
Total head slurry & $43 \mathrm{~m}$ & $45 \mathrm{~m}$ \\
Working pressure & $486 \mathrm{kPa}$ & $559 \mathrm{kPa}$ \\
Power consumption & $65 \mathrm{~kW}$ & $43 \mathrm{~kW}$ \\
\hline
\end{tabular}

The results in Table 1 demonstrate the strong effect of the solids content on the pipeline diameter and the energy effectiveness. Furthermore, the static head here accounts for about half of the consumed power. With this span of solids concentrations and the considered particle size distribution friction loss gradients may become practically similar when expressed in metre of slurry per metre of pipeline. It tends be so because the increased losses due to the required increase in velocity with pipeline diameter to avoid deposition are mainly balanced by the decrease in losses with diameter.

With the thickener located at the disposal area the placement is assumed to take place from the elevated position where the thickener underflow would discharge for many years in sequence via approximately 300 $\mathrm{m}$ long pipelines at $30 \mathrm{~m}$ lower elevation. Underflow pumping of $80 \mathrm{t} / \mathrm{h}$ at $71 \mathrm{w} \%$ with a flow rate of about $61 \mathrm{~m}^{3} / \mathrm{h}$ at a pressure of about $4.1 \mathrm{kPa} / \mathrm{m}$ in a $0.15 \mathrm{~m}$ pipeline is considered based on a yield stress of $150 \mathrm{~Pa}$ and Bingham plastic viscosity 0.1 Pas. With centrifugal pumps working at a total efficiency of about $50 \%$ the power requirement is about $24 \mathrm{~kW}$. Thus, the total pumping requirements for pumping the dilute feed concentrations 21 and 33w\% (Table 1) and thickened tailings with centrifugal pumps are 89 and $67 \mathrm{~kW}$, respectively. 
With the thickener located at the plant a high pressure positive displacement pump system is considered for direct delivery to the placement about 2,300 $\mathrm{m}$ away. Based on the operating parameters assumed above for the underflow pumping a pressure of about $9.2 \mathrm{MPa}$ would require $183 \mathrm{~kW}$ in a $0.150 \mathrm{~m}$ diameter pipeline (pump efficiency 85\%). A summary of the operating data forming a basis for estimation of capital and operating costs are given in Table 2.

Table 2 Operating data in the example with the thickener at the disposal area for dilute feed at 20.6 or $32.9 \mathrm{w} \%$ and thickener underflow pumping with centrifugal pumps totally consuming 89 and $67 \mathrm{~kW}$, respectively. Comparison with the thickener at the concentrator for high pressure pumping with a positive displacement pump using $183 \mathrm{~kW}$

\begin{tabular}{lccc}
\hline Solids concentration by mass & $20.6 \%$ & $32.9 \%$ & $71 \%$ \\
Pipeline diameter & $0.25 \mathrm{~m}$ & $0.20 \mathrm{~m}$ & $0.15 \mathrm{~m}$ \\
Working pressure & $486 \mathrm{kPa}$ & $559 \mathrm{kPa}$ & $9,200 \mathrm{kPa}$ \\
Power consumption & $89 \mathrm{~kW}$ & $67 \mathrm{~kW}$ & $183 \mathrm{~kW}$ \\
\hline
\end{tabular}

The operating data in Table 2 form a basis for a direct cost comparison for the pumping-thickening system with the exclusions taken up by Paterson (2005).

\subsection{Centrifugal pump performance-thickened tailings}

Few studies on the pump performance with authentic tailings slurries are available. Cooke (2007) presented results for various tailings products for solids concentrations by volume of up to $38 \%$ with yield stresses from 60 to nearly $100 \mathrm{~Pa}$. He reported head and efficiency reductions of less than about $10 \%$ with a standard centrifugal slurry pump with a $0.365 \mathrm{~m}$ diameter impeller.

Sellgren et al. (2011) presented performance results for two tailings products for a pump with a standard closed shroud impeller (diameter $0.31 \mathrm{~m}$ ) or an open shroud type having an auger-like inducer. The head could not be maintained for flow rates less than about $50 \%$ of the BEP for the open and closed impeller at solids concentrations by volume, C, of 49 and $47 \%$, respectively, for the fine tailings (median size $50 \mu \mathrm{m}$ ). The corresponding yield stresses were about 225 and $175 \mathrm{~Pa}$ as evaluated from pipeline loop data.

When operating a centrifugal pump with water in excess of a point where cavitation begins, this is followed by rapidly increasing drops in both head and efficiency. It is indicated in the literature that cavitational behaviour may occur at lower flow rates with non-Newtonian slurries than for water. The observed difficulties in maintaining the head when handling highly thickened tailings slurries for moderately low flow rates together with possible cavitation tendencies for flow rates close to BEP influence the operation in practice.

\section{$2 \quad$ Objective}

The objective is to present advances in the use of centrifugal pumps for thickened tailings and discuss experimental results and criteria for stable operating conditions, cavitation tendencies and deratings in pumping head and efficiency.

\section{Character isation}

\section{1 Derating of pump curves}

When pumping slurries the relative reduction of the water head and efficiency for a constant flow rate and rotary speed may be defined by the following factors and ratios, Figure 2. 


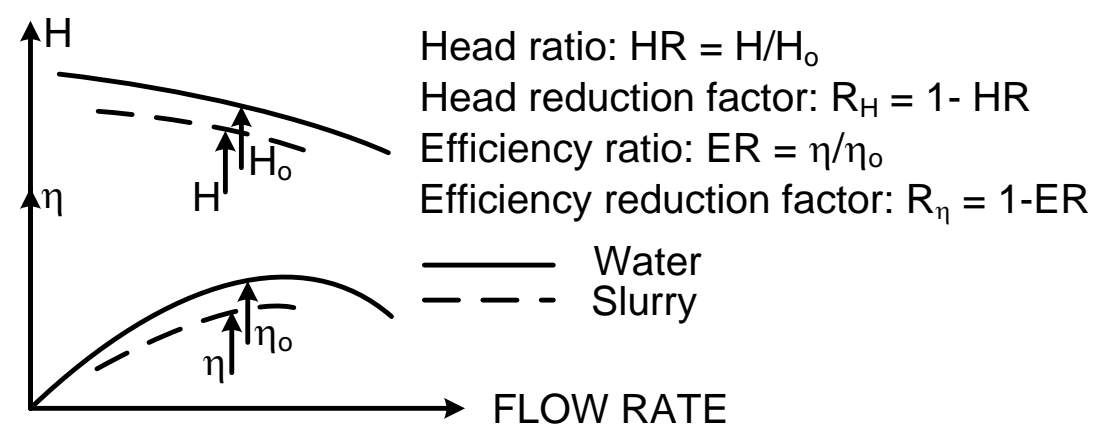

Figure 2 Sketch defining the reduction in head and efficiency of a centrifugal pump pumping a solids water mixture. $\mathrm{H}$ and $\mathrm{H}_{0}$ are heads in slurry and water service, respectively. The corresponding efficiencies are $\eta$ and $\eta_{0}$

To be able to produce a required head, $\mathrm{H}$, of slurry, the pump must be capable of producing a head of water, $\mathrm{H}_{0}$ :

$$
H_{0}=H / H R
$$

which means that the pump water rotary speed has to be increased.

The pump used by Sellgren et al. (2011) was an all metal pump with a semi-volute shell, $0.1 \mathrm{~m}$ diameter suction inlet, $0.075 \mathrm{~m}$ discharge and a $0.31 \mathrm{~m}$ diameter three-vane impeller. Detailed derating results for the open shroud impeller with an inducer are shown in Figure 3, where the head could not be maintained when $C$ increased from 47 to $49 \%$.
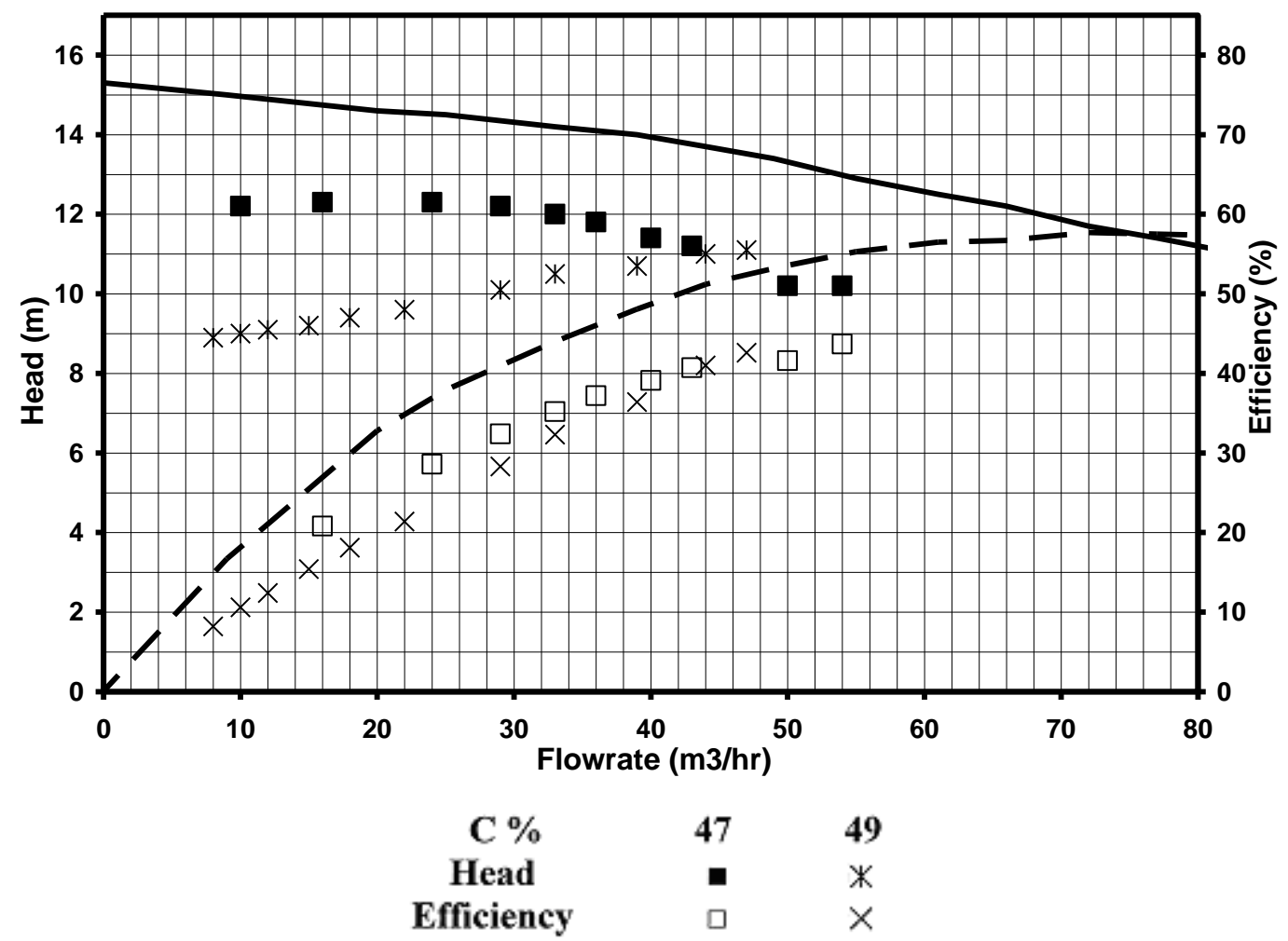

Figure 3 Pump solids effect for $C$ values of 47 and $49 \%$ with the open shroud impeller with an inducer. The tailings products had a median particle size of about $50 \mu \mathrm{m}$. Solids density $2,710 \mathrm{~kg} / \mathrm{m}^{3}$ 
It follows from Figure 3 how the head cannot be maintained for $C=49 \%$ and flow rates below about $45 \mathrm{~m}^{3} / \mathrm{h}$ corresponding to $\mathrm{Q} / \mathrm{Q}_{\mathrm{BEP}}$ about 0.5 where $\mathrm{Q}$ and $\mathrm{Q}_{\mathrm{BEP}}$ are the considered flow rate and the flow rate at BEP, respectively. The tendency of a drop in head could not be met by an increase in rotary speed.

Corresponding results for the same tailings product with the closed impeller pump showed a diverging effect at a $\mathrm{Q} / \mathrm{Q}_{\mathrm{BEP}}$ of about 0.5 for both 47 and $49 \%$, see Figure 4.
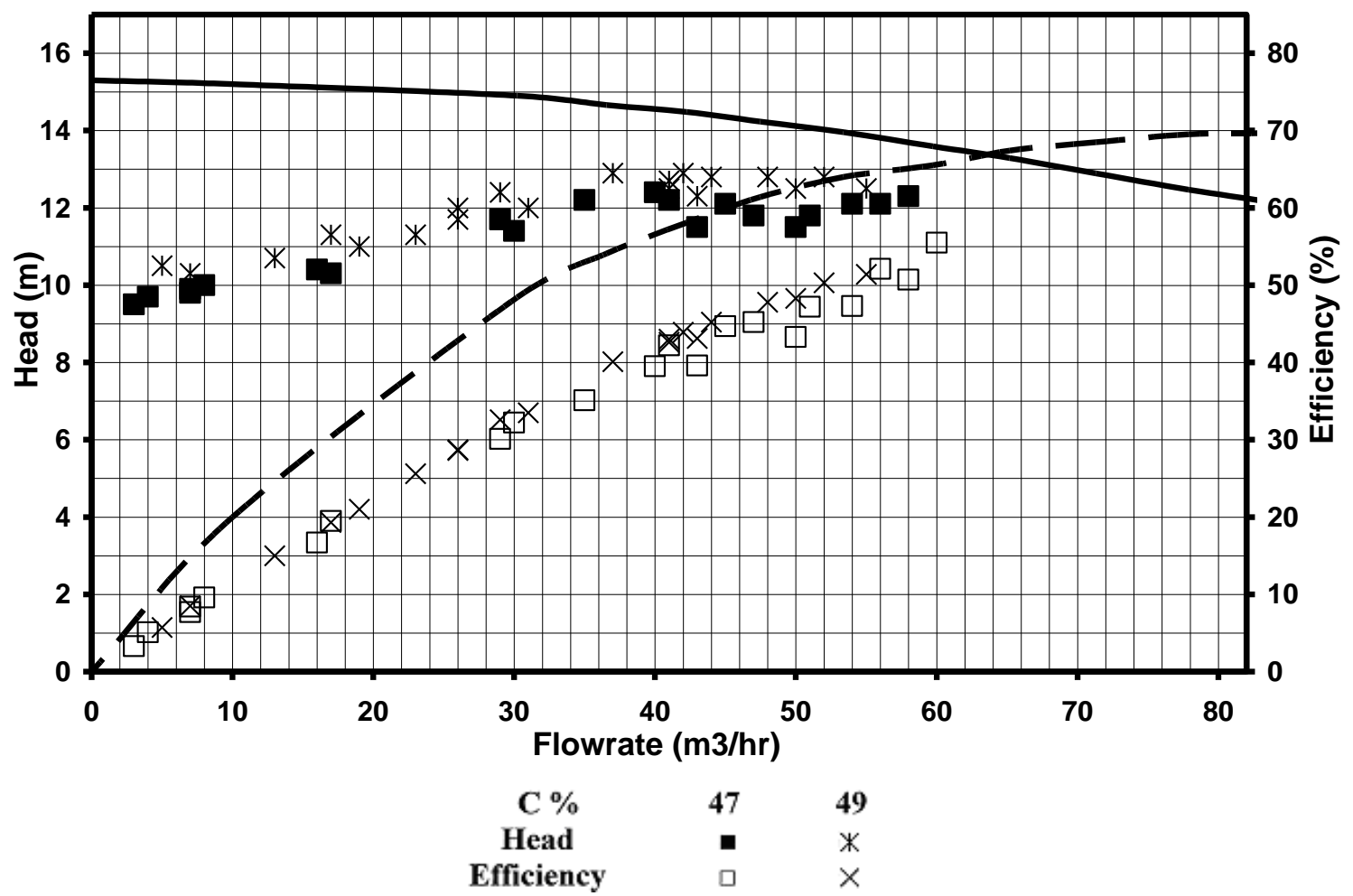

Figure 4 Pump solids effect for the standard pump with closed impeller C $=47$ and $49 \%$, with the same tailings product as in Figure 3

As seen in Figure 4, 47\% was not reached for the standard configuration to avoid diverging head tendencies for moderately low flow rates. No diverging effects were observed at $C=40 \%$. A reasonable assumption is that an upper limit for a stable head curve here is about $45 \%$.

Unfortunately, experimental data were not available closer to the BEP value than about $60 \%$ for the highest solids concentrations $47-49 \%$. Performance reductions in head and efficiency from Figures 3 and 4 were therefore extrapolated into the BEP region to be 15 and 20\% at a maximum. The study (Sellgren et al., 2011) also covered a coarser tailings product with median particle size $70 \mu \mathrm{m}$. The two products had maximum particle sizes of about $400 \mu \mathrm{m}$ and solids density $2,710 \mathrm{~kg} / \mathrm{m}^{3}$. Evaluated maximum reductions in head and efficiency in the BEP region are summarised in Table 3.

Table 3 Summary of experimental performance results for two tailings products with a standard closed shroud impeller and an open shroud type having an auger-like inducer, with impeller diameter $0.31 \mathrm{~m}$ (Sellgren et al., 2011). Solids concentration by volume, $45-49 \%$

\begin{tabular}{lcc}
\hline & Coarse & Fine \\
\hline Average particle size & $70 \mathrm{~d}_{50} \mu \mathrm{m}$ & $50 \mathrm{~d}_{50} \mu \mathrm{m}$ \\
Average particle size & $20 \%<20 \mu \mathrm{m}$ & $30 \%<20 \mu \mathrm{m}$ \\
Reduction factor, $\mathbf{R}_{\mathbf{h}}$ & $7 \%$ & $15 \%$ \\
Reduction factor, $\mathbf{R}_{\mathbf{n}}$ & $14 \%$ & $20 \%$ \\
\hline
\end{tabular}


The deratings in Table 3 were about 1.5 times larger for the finer tailings. Furthermore, the pipeline friction losses in 0.075 and $0.15 \mathrm{~m}$ in diameter pipelines were also about 1.5 times higher for the finer tailings slurry. For lower concentrations about $40 \%$, the reductions in head and efficiency for the finer product were about 4 and $7 \%$, respectively.

\section{2 Cavitation-suction performance}

Cavitation in a pump occurs when the local pressure falls below the vapour pressure of the liquid, i.e. the pressure at which the liquid boils. When cavitation starts, the pump head and efficiency decrease. Incipient cavitation can be defined by a $3 \%$ reduction after correcting the pump head curve $\mathrm{H}_{\mathrm{w}}$ for the effect of solids, see Figure 5.

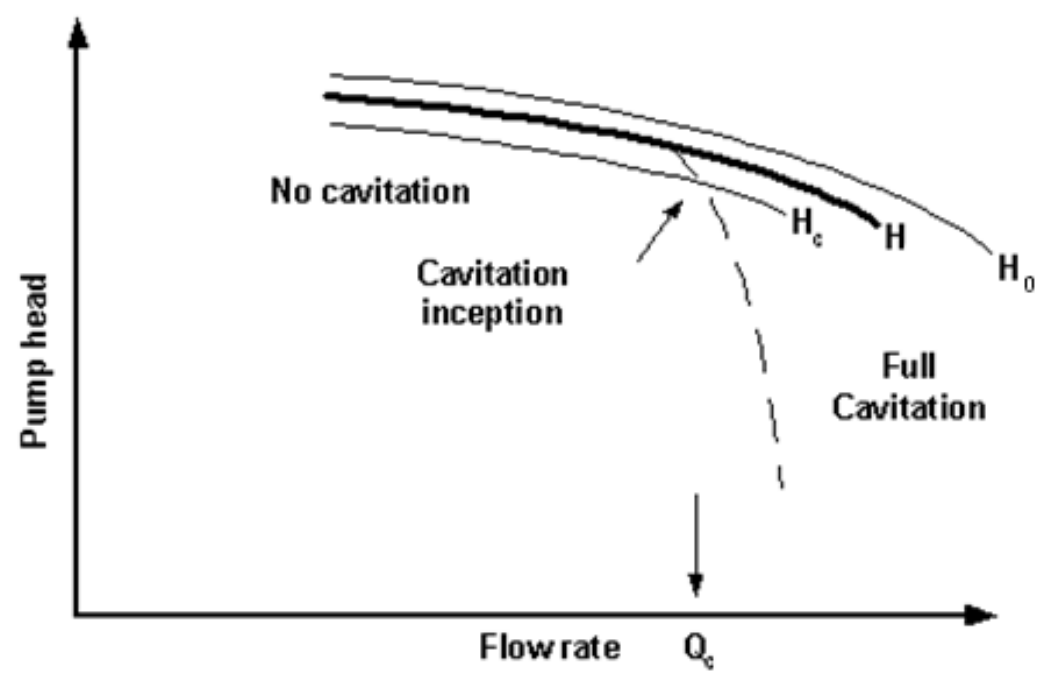

Figure 5 Definition of the cavitation inception point ( $f$ low rate $Q_{c}$ ) when pumping slurries. $H_{0}$ and $H$ are heads for water and slurry, respectively. The influence of cavitation, $H_{c}$, is defined as a $3 \%$ reduction of the head $(\mathrm{H})$ developed in slurry service, Whitlock et al. (2001)

To ensure operation without cavitation, it is required that the absolute pressure at the pump impeller eye exceeds the vapour pressure by a certain margin. By convention, the required absolute pressure at the pump entrance is expressed in terms of head of the mixture being pumped, using the term Net Positive Suction Head Required (NPSHR). The NPSHR is usually specified by the pump manufacturer based on tests with water. Elaborate closed vacuum tank arrangements are used to establish NPSHR-curves for water. NPSHR increases for increased flow rate and rotary speed. It is an established practise to use the water NPSHR from the pump curves for slurries and consider the mixture as an equivalent fluid, i.e. the slurry has all the properties of water except the density which attains the slurry value.

In a normal open tank-suction pipeline arrangement for positive head delivery of slurry to the pump an energy balance determines the available head, NPSHA, at the pump entrance. With the gauge suction pressure, $p_{\mathrm{gs}}$, measured then the available NPSHA is given directly as:

$$
\mathrm{NPSHA}=\left(p_{\mathrm{atm}}-\mathrm{p}_{\mathrm{vp}}+\mathrm{p}_{\mathrm{gs}}\right) / \rho \mathrm{g}+\mathrm{V}^{2} / 2 \mathrm{~g}
$$

where $p_{a t m}$, is the atmospheric pressure, $p_{v p}$ the vapour pressure and where $\rho$ is the slurry density and $g$ the acceleration due to gravity. The last term is the velocity head in $\mathrm{m}$ of slurry ( $\mathrm{V}$ is velocity).

NPSHA from Equation (2) decreases with flow rate while NPSHR increases defining a cross-over point NPSHA = NPSHR, theoretically the flow rate for incipient cavitation. Thus, a criterion for cavitation-free operation with some margin means that:

$$
\text { NPSHA > NPSHR }
$$


In the study by Sellgren et al. (2011), the suction side pressure was measured at the pump in a $3 \mathrm{~m}$ long suction pipeline with a diameter of $0.1 \mathrm{~m}$ mounted at the bottom of a vertical cylindrical tank with a diameter of $0.44 \mathrm{~m}$ and a height of $1.8 \mathrm{~m}$. Evaluated NPSHA-values at the highest concentration volumetric concentration $\left(49 \%\right.$, slurry density $\left.1,840 \mathrm{~kg} / \mathrm{m}^{3}\right)$ in Equation (2) at $\mathrm{Q} / \mathrm{Q}_{\text {BEP }}$ values of 60 and $40 \%$ were 4.34 and $4.63 \mathrm{~m}$ slurry, respectively. The corresponding NPSHR values from the manufacturer's chart were 2.2 and $1.3 \mathrm{~m}$ for water. NPSHA was thus $4.34-2.2=2.1 \mathrm{~m}$ over the NPSHR-value at a $\mathrm{Q} / \mathrm{Q}_{\text {BEP }}$ of about $60 \%$ and $4.63-1.3=3.3 \mathrm{~m}$ at $40 \%$. The values are about 2 and 3.5 times the water values. It follows that the margins are high, however, they do not give a sufficient basis for estimations of cavitational tendencies for flow rates in a region closer to the BEP.

Kabamba (2007) carried out extensive experimental studies on the pump performance covering the BEP region for highly viscous and non-Newtonian slurries of kaolin, bentonite and a CMC fluid. The kaolin slurries had yield stresses of 100 and $185 \mathrm{~Pa}$ at volumetric concentrations of 17 and 19\%, respectively. Kabamba used two standard pumps, one was of the same type and size as used by Sellgren et al. (2011), see Table 3 and Figure 4, i.e. an all metal unit with a semi-volute shell, $0.1 \mathrm{~m}$ diameter suction inlet, $0.075 \mathrm{~m}$ discharge and a $0.3 \mathrm{~m}$ diameter three-vane impeller. The other was a $0.15 \times 0.1 \mathrm{~m}$ all metal fivevane pump with an impeller diameter of $0.365 \mathrm{~m}$.

In the test loop a cylindrical-conical tank with a volume of about $3 \mathrm{~m}^{3}$ was connected to the larger pump via a pipeline about $3 \mathrm{~m}$ long and $0.15 \mathrm{~m}$ in diameter. The smaller pump suction side pipeline was about $1 \mathrm{~m}$ longer and had a $90^{\circ}$ elbow. The larger pump was gland water sealed while the smaller pump had a mechanical seal.

The evaluations by Kabamba (2007) were focused on the de-rating in head and efficiency and comparisons with criteria by Walker and Goulas (1984) and others. The detailed pump operating data available in appendences in Kabambas work have been evaluated here in terms of suction performance by Wennberg (2011). Results for the kaolin data are given for the two pumps in Figures 6 and 7. 

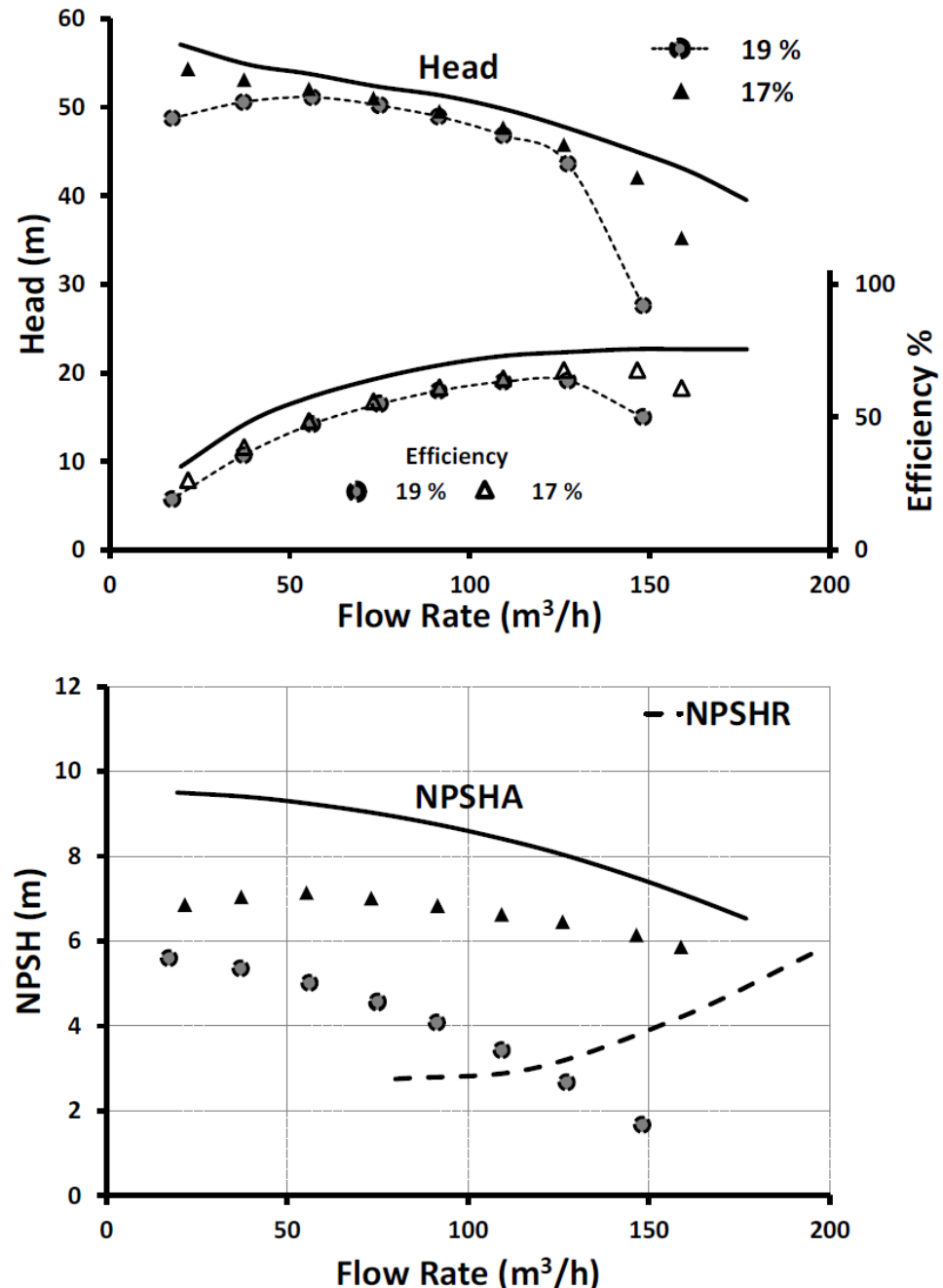

Figure 6 Incipient cavitation results for kaolin slurry at $C=17$ and 19\% for 1,900 rpm with the closed shroud standard pump with a $0.31 \mathrm{~m}$ diameter impeller (Wennberg, 2011), based on measured data by (Kabamba, 2007) 

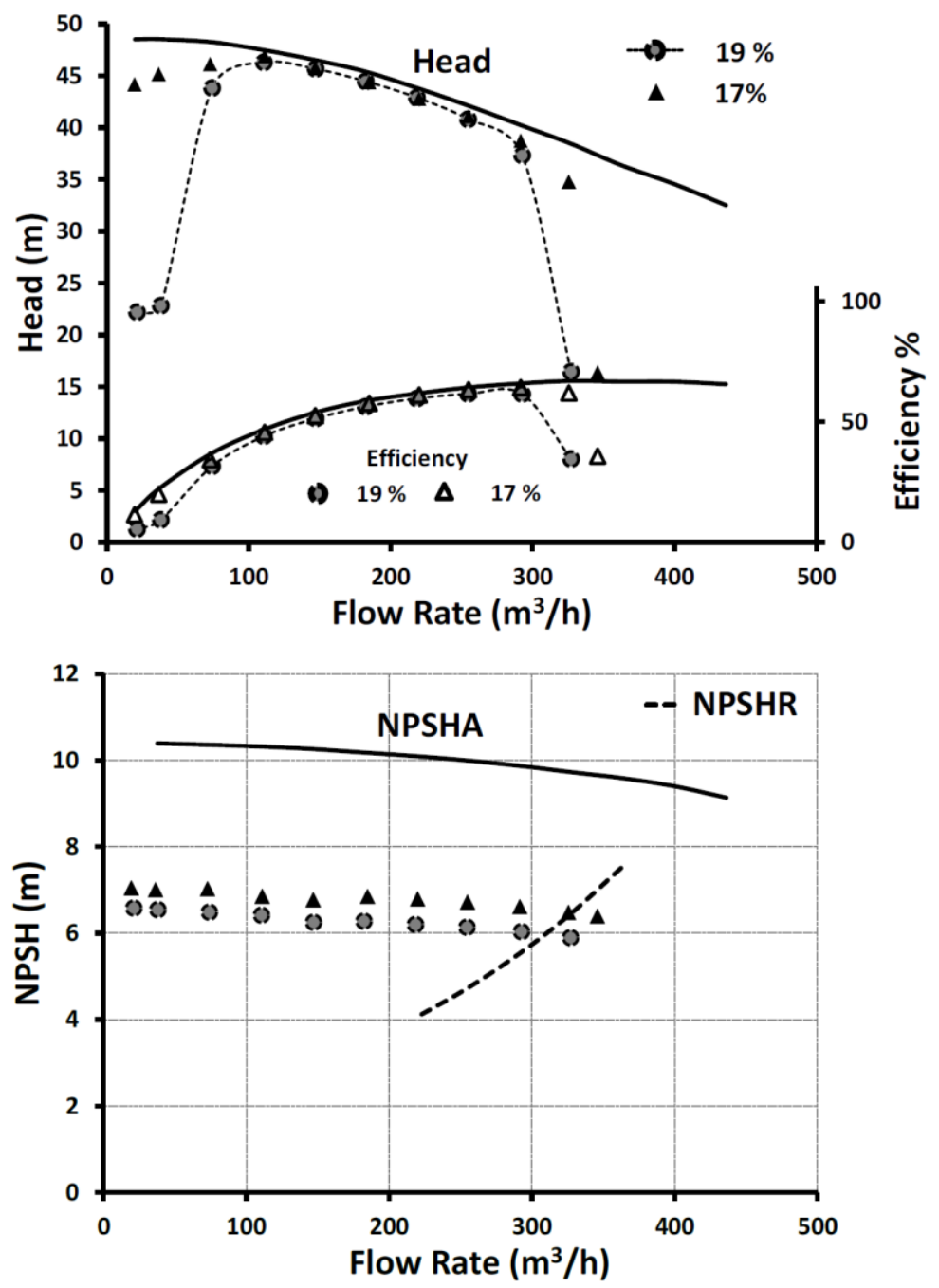

Figure 7 Incipient cavitation results for kaolin slurry at $C=17$ and $19 \%$ at 1,400 rpm for a 0.15 by $0.1 \mathrm{~m}$ five-vane all metal pump with a $0.365 \mathrm{~m}$ impeller diameter (Wennberg, 2011), based on measured data by Kabamba (2007)

For the briefly described tank-suction pipeline set-up, it follows from Figure 6 for $\mathrm{C}=17$ and $19 \%$ that incipient cavitation with drops in head and efficiency occurred at 130 and $150 \mathrm{~m}^{3} / \mathrm{h}$, respectively, which is about 75 and $80 \%$ of $Q_{B E P}$, respectively. It also follows that NPSHA approximately equals NPSHR for water at $19 \%$ while it exceeds the NPSHR-value at $17 \%$. No cavitation indications were observed for 1,300 and $1,600 \mathrm{rpm}$. For the larger pump in Figure 7 the inception appeared at about 300 and $315 \mathrm{~m}^{3} / \mathrm{h}$ for $\mathrm{C}=17$

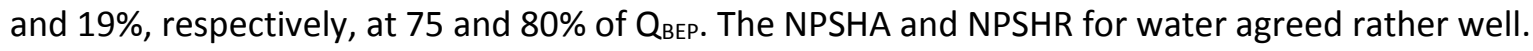

\section{Discussion}

\section{1 Suction performance}

Roudnev (2004) and Bootle (2006) discussed experimental results with NPSHR of up to double the water value for non-settling type of slurries with high yield stresses. Furthermore, they discussed that the greater NPSH-requirement can be related to blockage tendencies in the pump entrance region. Adverse suction performance effects are further discussed by Wennberg (2010), who also identified an installation and observed how a standard pump operating at $0.5 \mathrm{Q}_{\text {BEP }}$ under a thickener showed no unstable head tendencies for a tailings slurry with an yield stress of nearly $200 \mathrm{~Pa}$. 
With a location of an underflow pump close to the thickener discharge the suction side pressure requirement should normally be fulfilled with a reasonable margin because it is located a considerable depth below the slurry surface level.

Following ANSI/HI (2005) for slurries an increase in NPSHR can generally be expected and it is suggested to divide the value of NPSHR on water by the head ratio, HR in addition to the margin normally used for water, thus:

$$
\text { NPSHA > NPSHR/HR }
$$

\section{2 Derating modelling}

Yield stress is often used as the upper limit for 'pumpability' and may reflect blockage tendencies in the entrance region. Yield stress is not necessarily a determining factor for the development of an unstable head curve (Wennberg et al., 2008), following results by Kabamba (2007) for a CMC-fluid with pseudoplastic property. Bootle (2006) reported kaolin results with yield stresses of 200 and 7.5 Pa giving practically the same reductions in efficiency, ER about 0.83 , with no reductions in head $(H R=1)$ for a pump with a large suction entrance and an inducer arrangement.

A derating method for head and efficiency when handling non-Newtonian slurries (Warman International, 1991) goes back to Walker and Goulas (1984) through a modified pump Reynolds number:

$$
\operatorname{Re}=\frac{\omega D_{i}^{2} \rho_{m}}{\eta}
$$

where $\omega$ is rotational speed, $D_{i}$, impeller size, $\rho_{m}$ slurry density and $\eta$ and (Bingham) plastic viscosity.

Authentic tailings derating results for a product with a similar median size $(70 \mu \mathrm{m})$ as the coarse tailings (Table 2) from Cooke (2007) and Sellgren et al. (2011) are roughly compared to the method in Figure 8.
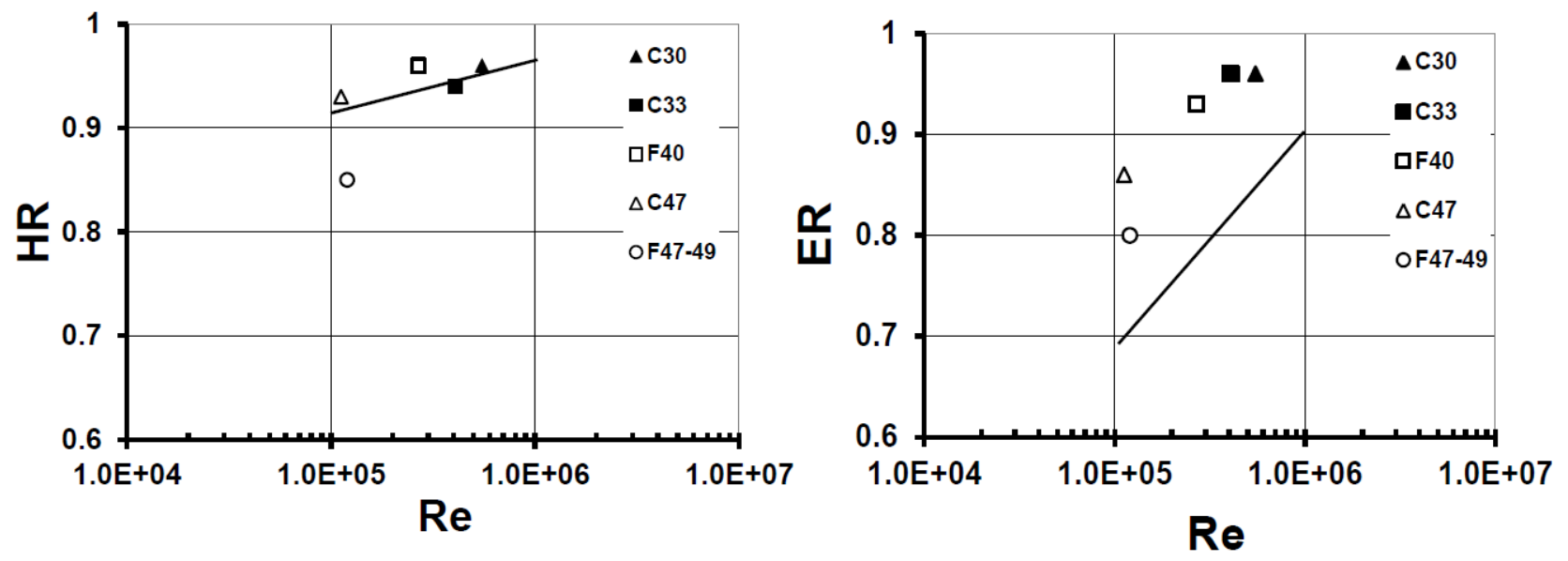

Figure 8 Comparison of deratings for authentic tailings results by Cooke (2007, filled marks) and Sellgren et al. (2011) with the Walker and Goulas (1984) derating method. F and C stands for median particle sizes of about 50 and $70 \mu \mathrm{m}$, respectively, and the numbers are volumetric concentrations. The filled lines within a limited Re-interval are approximate derating curves from the chart (Warman International, 1991)

The comparisons in Figure 8 support mainly the trends summarised by Cooke (2007) with a reasonable estimation for head derating and a tendency to over predict the effect on efficiency, especially for larger pumps. However, no size effect was seen here for the 0.365 and $0.31 \mathrm{~m}$ diameter impeller pumps used by Cooke (2007) and Sellgren et al. (2011), respectively. 
Thickened tailings typically have average particle sizes of 20-100 $\mu \mathrm{m}$ with maximum sizes of up to about $500 \mu \mathrm{m}$. The corresponding slurries cover an intermediate area between homogeneously and heterogeneously flowing mixtures. For ground rock metal mine tailings, the finer (clay-sized) particles are not normally clay minerals but rock flour, Fourie (2003), a dissimilarity also marked by Robinsky (1999). The two-component behaviour due to the content of large particles has been clearly identified for thickened tailings pipeline transport (Pullum, 2007). The tailings slurry flow fields in pumps and open surface gravity flow placement in the disposal area are also influenced by the two-component behaviour. Therefore, the viscous parameter (Equation (5)) may not be sufficient to describe the pump curve derating mechanisms for the tailings slurries discussed here.

\section{Conclusions}

Maximum reductions in head and efficiency have been found to be about 15 and $20 \%$, respectively, for a pump with a standard closed shroud impeller and an open shroud type having an auger-like inducer for solids concentrations by volume of about 47 and $49 \%$, respectively. Yield stresses were up to $200 \mathrm{~Pa}$ as an average and evaluated from pipeline loop testing. However, unstable head curves were observed for flow rates less than about $50 \%$ of the best efficiency values (BEP). The slightly higher sensitivity to an unstable head for the standard closed impeller can be weighted to a $10 \%$ higher efficiency compared to the open version with an auger-inducer.

Thickened tailings have typically average particle sizes of 20-100 $\mu \mathrm{m}$ with maximum sizes of up to about $500 \mu \mathrm{m}$. The corresponding slurries cover an intermediate area between homogeneously and heterogeneously flowing mixtures, where rheological modelling may not be sufficient. Performance data for authentic and typical tailings slurries with volumetric solids concentrations well above $40 \%$ were investigated here for a rather small pump. Deratings in head and efficiency, effects related to unstable head tendencies and suction performance can be expected to diminish for larger pumps.

It has been reported for highly concentrated slurries that cavitational behaviour with drops in head and efficiency may occur at lower flow rates than for water in the BEP-region. The experimental data for the tailings above did not cover this region. Test data by Kabamba (2007) for the same type and size of standard pump with closed shroud impeller were evaluated here for kaolin slurry with a yield stress of $185 \mathrm{~Pa}$. Incipient cavitation was found to be from $75 \%$ of the flow rate at BEP.

\section{Acknow l edgements}

I express my thanks to Battha Kabamba, Cape Peninsula University of Technology, South Africa, for providing additional information about his experimental work referred to in this paper. I am also appreciative of the contributions of Robert Visintainer, Graeme Addie and Lee Whitlock, GIW Industries Inc., U.S.A.

\section{References}

ANSI/HI (2005) Rotodynamic (Centrifugal) Slurry Pump Standard, 12.1-12.6, Hydraulic Institute, May 2005, $110 \mathrm{p}$.

Bootle, M.J. (2006) Practical Aspects of Transporting Past with Rotodynamic Slurry Pumps, in Proceedings Ninth International Seminar on Paste and Thickened Tailings (Paste06), R.J. Jewell, S. Lawson and P. Newman (eds), 3-7 April 2006, Limerick, Ireland, Australian Centre for Geomechanics, Perth, pp. 413-427.

Cooke, R. (2007) Thickened and Paste Tailings Pipeline Systems-Design Procedure, Part 2, in Proceedings Tenth International Seminar on Paste and Thickened Tailings (Paste07), A.B. Fourie and R.J. Jewell (eds), 13-15 March 2007, Perth, Australia, Australian Centre for Geomechanics, Perth, pp. 129-140.

Fourie, A. (2003) Important material characterisation of thickened tailings, in Proceedings International Seminar on Paste and Thickened Tailings (Paste2003), 14-16 May 2003, Melbourne, Australia, Australian Centre for Geomechanics, Perth, Section 29.

Kabamba, B.M. (2007) Evaluation of derating procedures or centrifugal performance, Magister Technologiae thesis, Cape Peninsula University of Tecnology, South Africa. 
Paterson, A.J.C. (2005) Determining the optimum location of a high rate thickener for a thickened tailings system, in Proceedings International Seminar on Paste and Thickened Tailings (Paste 2005), R.J. Jewell and S. Barrera (eds), 20-22 April 2005, Santiago, Chile, Australian Centre for Geomechanics, Perth, pp. 177-184.

Pullum, L. (2007) Pipelining tailings, pastes and backfill, in Proceedings 10th International Seminar on Paste and Thickened Tailings (Paste2011), R.J. Jewell and A.B. Fourie (eds), 13-15 March 2007, Perth, Australia, Australian Centre for Geomechanics, Perth, pp. 113-128.

Robinsky, E.I. (1999) Thickened Tailings Disposal in the Mining Industry, Quebecor Printpak, Toronto, Canada.

Roudnev, A.S. (2004) Slurry pump suction performance considerations, in Proceedings 16th International Conference on Hydrotransport, BHR Group, Santiago, Chile, pp. 137-150.

Sellgren, A., Mustafa A., Addie, G.A. and Whitlock, L. (2011) Performance of Different Centrifugal Pump Impeller Configurations When Pumping Thickened Tailings, in Proceedings 14th International Seminar on Paste and Thickened Tailings (Paste2011), R.J. Jewell and A.B. Fourie (eds), 5-7 April 2011, Perth, Australia, Australian Centre for Geomechanics, Perth, pp. 405-416.

Sellgren, A., Addie, G. and Whitlock, L. (2005) Technical-Economical Feasibility of Using Centrifugal Pumps in High-Density Thickened Tailings Slurry Systems, in Proceedings Eighth International Seminar on Paste and Thickened Tailings (Paste05), R.J. Jewell and S. Barrera (eds), 20-22 April 2005, Santiago, Chile, Australian Centre for Geomechanics, Perth, pp. 195-206.

Walker, C.I. and Goulas, A. (1984) Performance characteristics of centrifugal pumps when handling homogeneous slurries, in Proceedings Institution of Mechanical Engineers, Vol. 198A, No. 1, pp. 41-49.

Warman International (1991) Pumping non-Newtonian slurries, Technical bulletin number 14, Warman International.

Wennberg, T. (2010) Transporting highly concentrated slurries with centrifugal pumps, The thickened minerals tailings example, Licentiate thesis, Department of Chemical Engineering, Geoscience and Mineral Processing, Luleå University of Technology, Lulea, Sweden, ISBN 978-91-7439-169-5.

Wennberg, T. (2011) Manuscript, Centrifugal slurry pump suction performance evaluations, LKAB, Sweden.

Wennberg, T., Sellgren, A. and Whitlock, L. (2008) Predicting the performance of centrifugal pumps when handling complex slurries, in Proceedings 14th International Conference on Transport and Sedimentation of Solids Particles, June 23-25, Saint Petersburg, Russia, pp. 324-333.

Whitlock L., Sellgren, A. and Wilson, K. (2001) Net Positive Suction Head Requirements for Centrifugal Slurry Pumps, Handbook of Conveying and Handling of Particulate Solids, 10 Elsevier Science B.V., pp. 491-497. 
Pipeline transport and rheology 